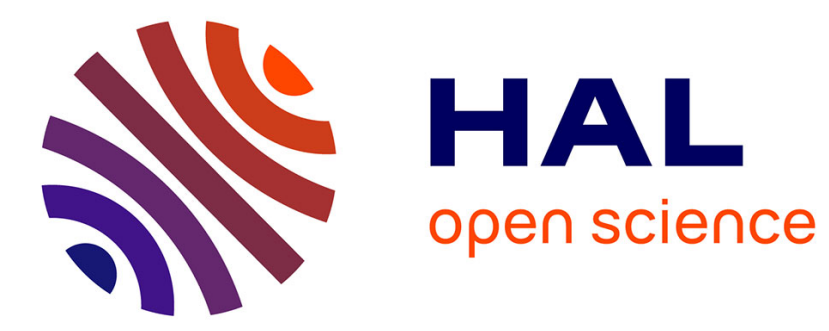

\title{
Low energy neutral beam production by laser vaporization of metals
}

\author{
C. Breton, C. de Michelis, W. Hecq, M. Mattioli
}

\section{To cite this version:}

C. Breton, C. de Michelis, W. Hecq, M. Mattioli. Low energy neutral beam production by laser vaporization of metals. Revue de Physique Appliquée, 1980, 15 (6), pp.1193-1200. 10.1051/rphysap:019800015060119300 . jpa-00244841

\section{HAL Id: jpa-00244841 https://hal.science/jpa-00244841}

Submitted on 1 Jan 1980

HAL is a multi-disciplinary open access archive for the deposit and dissemination of scientific research documents, whether they are published or not. The documents may come from teaching and research institutions in France or abroad, or from public or private research centers.
L'archive ouverte pluridisciplinaire HAL, est destinée au dépôt et à la diffusion de documents scientifiques de niveau recherche, publiés ou non, émanant des établissements d'enseignement et de recherche français ou étrangers, des laboratoires publics ou privés. 


\title{
Low energy neutral beam production by laser vaporization of metals
}

\author{
C. Breton, C. de Michelis, W. Hecq and M. Mattioli \\ Association EURATOM-CEA sur la fusion, Département de Physique du Plasma et de la Fusion Contrôlée, \\ Centre d'Etudes Nucléaires, Boîte Postale n 6, 92260 Fontenay-aux-Roses, France
}

(Reçu le 27 décembre 1979, accepté le 28 février 1980)

\begin{abstract}
Résumé. - Les faisceaux d'atomes de faible énergie $(0,1-10 \mathrm{eV})$ produits par évaporation de feuilles métalliques minces soumises à un tir laser sont caractérisés quantitativement. Dans les conditions géométriques d'implantation sur le Tokamak TFR la méthode décrite permet d'injecter $10^{15}$ atomes pendant $300 \mu \mathrm{s}$.
\end{abstract}

\begin{abstract}
We have quantitatively studied the production of low energy $(0.1-10 \mathrm{eV})$ metal neutral beams by laser vaporization of thin metal foils. For the experimental geometry available on the TFR tokamak, this technique results in the injection of $10^{15}$ neutrals in a time of $\sim 300 \mu \mathrm{s}$.
\end{abstract}

1. Introduction. - The study of impurities behaviour in tokamak devices is probably one of the most important subjects on the way to the development of fusion. Indeed, radiation losses due to line radiation from highly (but incompletely) stripped heavy impurities (as well as bremsstrahlung from light impurities) can eventually prevent the operation of fusion reactors.

The impurity dynamics is generally studied by looking at the behaviour of impurities naturally present in the plasma [1]. However, in this case one has no influence on the origin of impurities and it is therefore difficult to interpret the experimental results. One way of preventing this difficulty is to inject in an already established plasma a short puff of a given impurity. This is often done by injecting a short gas puff $[2,3,4]$. However, pulsed gas injection of impurities has several drawbacks. First of all, there is only a limited number of available gases. Secondly, due to the thermal velocity of room temperature gases, the injected pulses have a width of several milliseconds, a time long compared to the relevant times for impurities in tokamak plasmas (i.e., diffusion time, ionization and recombination times). Thirdly, and equally important, injected gas particles have low energies, and this prevents them from penetrating the scrape-off region. This problem is generally overcome by overflooding the edge of the plasma, in order to get sufficient impurity penetration; unfortunately, this solution has the drawback of cooling the plasma edge, thus modifying the base plasma.

These problems have been overcome by the injection of metallic neutral beams produced by a laser technique. These neutral sources have been proposed by Friichtenicht [5], who developed a laser vaporization technique in which a thin layer of the material to be vaporized (almost all metals can be used) is deposited on a glass slide and the laser is focused onto the material from the rear through the glass substratum. Marmar et al. [6] used this technique to inject aluminium atoms into a tokamak plasma, then following the emission of aluminium ions by vacuum ultraviolet spectroscopy. The TFR Group [7] used the same technique to inject molybdenum atoms into the TFR plasma, in order to help in the identification of highly stripped molybdenum ion spectral lines. A few other authors have studied this neutral beam production technique $[8,9]$, but were mainly interested in the surface conditions under laser irradiation. As a consequence, only a few quantitative data in the literature can be used when planning an impurity injection experiment on a fusion oriented plasma.

This paper is devoted to a systematic quantitative study of metallic neutral beams produced by laser vaporization. Besides the interest outlined above, atomic beams thus produced are also useful in the study of atomic collisions at low energies (from a few tenths of $\mathrm{eV}$ to several $\mathrm{eV}$ ). Indeed, these beams have an energy range which is difficult to attain with thermal and charge-exchange neutral beams [10].

2. Experimental set-up. - The experimental set-up is shown in figure 1, and is described in the following. 


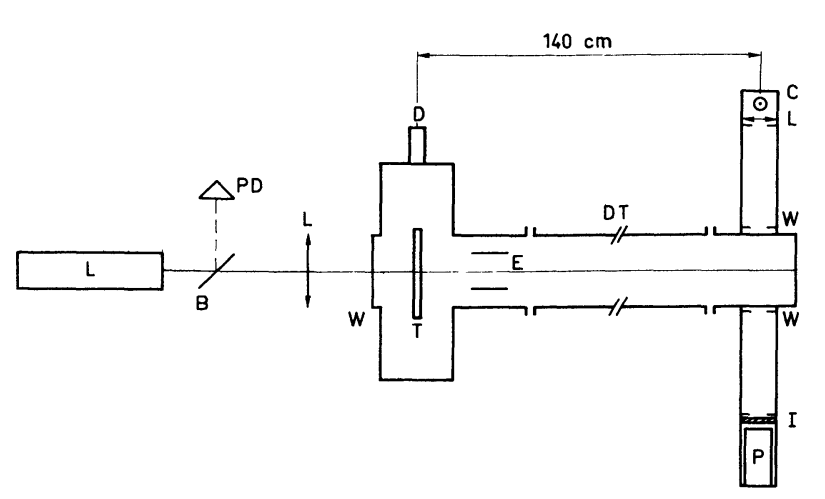

Fig. 1. - Experimental set-up. L : laser; PD : photodiode; B : beam-splitter; L : lens; W : quartz window; T : target; $\mathrm{D}:$ mechanism to move the target under vacuum; $\mathrm{E}$ : deflection plates; DT : drift tube; C : light source; I : interference filter; $\mathrm{P}:$ photomultiplier.

2.1 LASER. - The laser used in this study is a $\mathrm{Nd}$ : Yag Q-switched laser delivering up to $1 \mathrm{~J}$ in a $40 \mathrm{~ns}$ pulse (output wavelength $1.06 \mu \mathrm{m}$ ). No precaution has been taken to assure an uniform spatial intensity distribution. Indeed, due to the fact that no mode selection was performed, temporal and spatial peaks were observed. However, the total pulse energy was reproducible to a few percent. The laser was focused by a $30 \mathrm{~cm}$ focal length lens on the target. Optimum neutral production conditions were selected either by working at a fixed energy and translating the focusing lens in order to vary the laser energy density on target, or by keeping the lens fixed and varying the laser energy. The maximum in neutral production was always found at the same value of energy density on target (see later), and we therefore chose the experimental conditions giving the larger number of neutrals (i. e., maximum laser energy and optimization by varying the lens to target distance).

We have also extensively used a ruby laser (output wavelength $0.69 \mu \mathrm{m}$ ) of identical performances. Within the experimental errors we always obtained the same results. We have therefore concluded that, for the experiments related here, the laser wavelength is of no importance. As a consequence, all the results reported here have been obtained with the $\mathrm{Nd}$ : Yag laser.

2.2 TARGET. - The best results published until now have been obtained by depositing a thin film of the chosen metal on a glass substratum (the laser being fired on the target from the rear through the substratum). However, this technique has the drawback that it is very difficult to deposit uniform layers more than a few $\mu \mathrm{m}$ thick, due to adherence problems. We have therefore mainly used a different target, using thin metal foils, held between a glass disc and a stainless-steel disc (target diameter $10 \mathrm{~cm}$ ). This latter had a great number of equally spaced holes $(5 \mathrm{~mm}$ diameter), within which the laser was fired. The target could be rotated and translated under vacuum, by remote-control operation, in order to perform a few hundred experiments before having to change the metal foil. The results reported here concern three metals, $\mathrm{Al}, \mathrm{Ni}$ and $\mathrm{Mo}$ of increasing atomic number and increasing boiling temperature (see Table I). $\mathrm{Al}$ has been chosen mainly in order to compare our results with those already published, $\mathrm{Ni}$ and Mo have

Table I.

$\begin{array}{cccc}\text { Element } & \text { Atomic no. } & \begin{array}{c}\text { Boiling } \\ \text { point }\left({ }^{\circ} \mathrm{C}\right)\end{array} & \begin{array}{c}\text { Specific } \\ \text { gravity } \\ \left(\text { at } 20^{\circ} \mathrm{C}\right)\end{array} \\ \overline{\mathrm{Al}} & - & - & - \\ \mathrm{Ni} & 13 & 2057 & 2.699 \\ \mathrm{Mo} & 42 & 2900 & 8.90 \\ & 42 & 4800 & 10.2\end{array}$

been chosen because of their interest to tokamak plasma research (since they are currently present in the limiter and liner).

Although all the results reported here have been obtained with metal foils, we have carefully compared the results obtained with $2 \mu \mathrm{m}$ thick Al metal foils to those obtained with $2 \mu \mathrm{m}$ thick Al deposited on the glass disc. No difference between the two targets could be found. Finally we have also tried to fire the laser on a metal foil held between two stainlesssteel discs i.e., no glass disc. As expected, the results were in this case much more irreproductible, but the total number of neutrals thus produced was considerably less (this is due to the fact that, when using the glass substratum, the hot plasma produced by laser irradiation cannot expand and therefore heat is efficiently conducted from the plasma to the remaining solid material).

2.3 VACUUM CHAMBER. - The target was in a vacuum chamber (designed in order to be directly used on the TFR tokamak) with a limit vacuum (turbomolecular pump) of $5 \times 10^{-7}$ torr. The vacuum in the chamber could be varied by means of a calibrated air leak. After the interaction chamber the resulting neutral beam was allowed to expand into a drift tube. A charged particle collector (consisting of two parallel plates, $10 \mathrm{~cm}$ long, $5 \mathrm{~cm}$ wide, and $5 \mathrm{~cm}$ apart, to which a voltage of up to several hundred volts could be applied) was located at the entrance of the drift tube. This charge collector was used to eliminate and measure the ions present in the beam.

The neutrals were detected in a resonant absorption cell, which could be placed either at the entrance or at the end of the $1.1 \mathrm{~m}$ long drift tube. The solid angles relative to these two cell positions (as measured from the target) were of $5 \times 10^{-2} \mathrm{sr}$ and $4 \times 10^{-3} \mathrm{sr}$, respectively. When the absorption cell was at the end of the drift tube, the geometry was such as to exactly simulate the injection conditions on the TFR tokamak (solid angle from the target $\Omega=4 \times 10^{-3} \mathrm{sr}$, 
target to plasma distance $1.4 \mathrm{~m}$ ). The absorption cell used hollow-cathode commercial lamps with the cathode made of the metal under study. The emitted light was made almost parallel by a quartz lens and then further collimated by a series of diaphragms ( $8 \mathrm{~mm}$ diameter), defining the incident light beam. After the interaction region (optical path $10 \mathrm{~cm}$ perpendicular to the neutral beam axis) a further series of diaphragms (aligned with the preceeding ones) helped in defining the beam, which then passed through $a \sim 50 \AA$ interference filter (chosen to match the transition under study) and was then detected by a 56 DUVP (quartz window) photomultiplier. The transitions used for the three elements which have been thoroughly studied have wavelengths of $3089.2 \AA$ for $\mathrm{Al}, 3524.5 \AA$ for $\mathrm{Ni}$, and 3132.6 for Mo.

The photomultiplier signal, together with the ion signal issued from the charge collector, was sent to an oscilloscope, triggered by the laser pulse, which therefore defines the origin of the time basis (Fig. 2). The neutral pulse duration is obviously a function (through the time of flight) of distance from target to absorption cell. With the cell at the end of the drift tube, the neutral pulse duration is typically of a few hundred $\mu$ s.

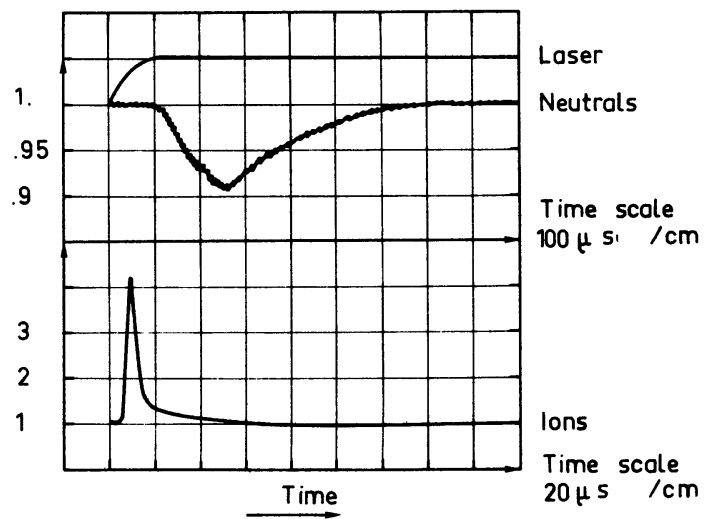

Fig. 2. - Experimental oscilloscope traces obtained with a $2 \mu \mathrm{m} \mathrm{Al}$ foil.

2.4 ANGUlaR DistRIBUTION OF THE NEUTRALS. The angular distribution of neutrals in the beam has been studied by inserting, before the absorption cell placed at the entrance of the drift tube, a $1 \mathrm{~cm}$ diameter diaphragm (solid angle $\sim 10^{-3} \mathrm{sr}$ ), which could be moved across the beam in the horizontal and vertical directions.

3. Absolute calibration. - The absorption signal being proportional to the neutral beam density (at least in the conditions where the absorption cell was placed after the drift tube, see later) it is easy to obtain, from the oscillograph traces on a relative scale the neutral density as function of time, with the laser pulse as time zero. The transit time from the target to the absorption cell specifies the neutral atom velocity (or energy). It is therefore straightforward to obtain on a relative scale, $n$ vs. $E$ curves ( $n$ being the neutral density, $\mathrm{cm}^{-3}$, and $E$ the neutral energy, eV). Given $n$ as a function of $E$, the flux density $F\left(\right.$ atom $\mathrm{cm}^{-2} \mathrm{~s}^{-1}$ ) of neutral atoms for any value of $E$ is given by

where

$$
F=n v
$$

$$
v=(2 E / m)^{1 / 2} .
$$

A more interesting way of presenting the results is to calculate the energy spectrum of the neutral beam. The number of atoms $\mathrm{d} N$ passing through a unit surface at a distance $R$ from the target in a time interval $\mathrm{d} t$ is given by

$$
\mathrm{d} N=F \mathrm{~d} t .
$$

By differentiating the expression of $\mathrm{d} t$ as function of energy, one easily obtains

$$
\left|\frac{\mathrm{d} N}{\mathrm{~d} E}\right|=\frac{n R}{2 E}
$$

from which the number of atoms per laser pulse contained in a given energy interval can be obtained. Of course, the total number of atoms can be obtained by integrating equation (3) up to the maximum energy.

It remains now to put an absolute value on the quantities defined above. The absolute value which is accessible to measurements is the beam density. This has been obtained in two different ways.

3.1 TOTAL NUMBer OF PARTIClES. - In this technique, the neutral beam in a given solid angle (defined by diaphragms) has been allowed to impinge on an appropriate substratum. The total number of particles deposited on the substratum after a given number of laser shots (typically one hundred) has then been measured by neutron activation techniques. The number thus obtained, divided by the number of experiments (see later for the reproducibility problem) has been compared with the integral obtained from the $\left|\frac{\mathrm{d} N}{\mathrm{~d} E}\right|$ vs. $E$ curves, thus allowing to obtain the absolute value.

3. 2 RESONANT ABSORPTION CALCULATIONS. - It is possible to obtain the absolute density directly from the resonant absorption measurement [11]. This is done in the following way. The neutral beam is supposed to expand spherically from the target, its velocity being $v_{R}$ at a distance $R$ from the target. Let $I(\omega)$ be the spectrum of the incident light, and let $r$ be the radius of the neutral beam in the measurement section (this radius being defined by an appropriate diaphragm; $r \ll R$ ). Absorption is determined by the natural line width and by the Doppler effect resulting from the velocity component parallel to $X$ (the geometry of the absorption measurement is shown in figure 3), i.e. $v_{X}=\frac{X}{R} v_{R}$. If the neutral 


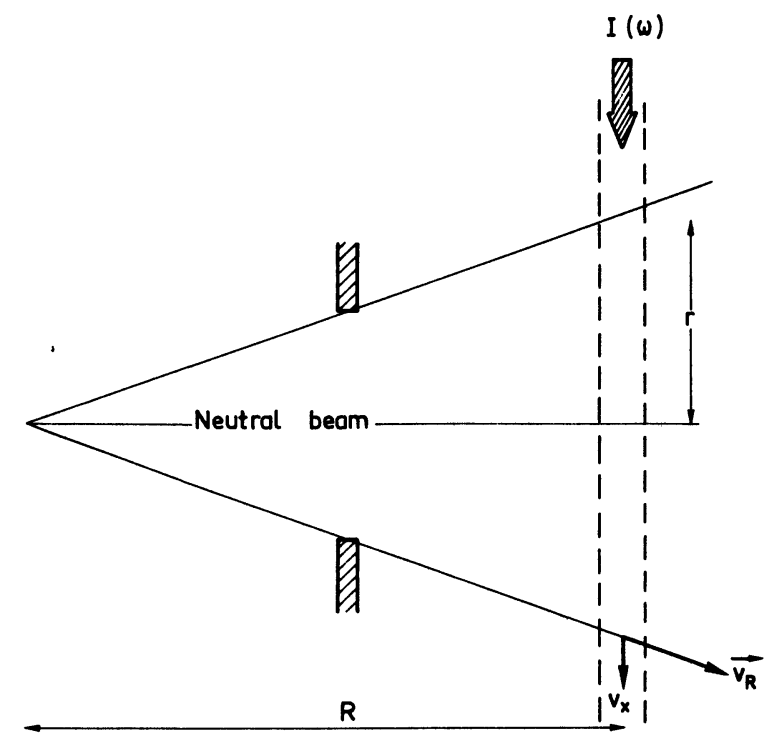

Fig. 3. - Geometry of the resonant absorption experiment.

density is constant along the $X$ direction (this hypothesis has been confirmed by measurements of the angular distribution of the beam density; see later), one has, for $|X| \leqslant r$,

$$
n(X, v)=n \delta\left(v-\frac{X}{R} v_{R}\right)
$$

Let the neutral beam be optically thin for the incident radiation, i.e. $I(\omega)=I(\omega, X)$ (this condition is satisfied when the absorption cell is at the end of the drift tube), then

$$
\begin{aligned}
\frac{\mathrm{d} I(\omega)}{\mathrm{d} X}=- & I(\omega) K_{0} \int n(X, v) \mathrm{d} v \times \\
& \times\left\{\frac{\gamma / 2 \pi}{(\gamma / 2)^{2}+\left[\omega-\omega_{0}(1-v / c)\right]^{2}}\right\}
\end{aligned}
$$

where $\omega_{0}$ is the incident frequency, $K_{0}$ the total absorption (Füchtbauer-Ladenburg law; note that $K_{0}$ is function of $\lambda$ and $A$ ) and the factor in the brackets in the integral is the Lorentz natural absorption function (for a resonant transition, $\gamma=A$, where $A$ is the transition probability).

By easy developments, one thus obtains, for the total transmitted signal $I_{t}$ (remember that we use an interference filter, admitting all the incident line)

$$
\begin{aligned}
I_{t}= & \int I_{\mathrm{t}}(\omega) \mathrm{d} \omega \\
= & \int I(\omega) \mathrm{d} \omega \exp \left[\left(-K_{0} n \frac{\gamma}{2 \pi}\right) \times\right. \\
& \left.\times \int_{-r}^{+r} \frac{\mathrm{d} X}{(\gamma / 2)^{2}+\left[\omega-\omega_{0}+\omega_{0} \frac{X}{R} \frac{v_{R}}{c}\right]^{2}}\right]
\end{aligned}
$$

It can be easily shown (by series development) that, if the beam is optically thin and the lamp spectral width is considerably larger than the Doppler width, the absorber signal is proportional to the beam density $n$. Since these two conditions are satisfied when the absorption cell is placed at the end of the drift tube, this fact has been used to deduce directly the relative beam density vs. energy from the absorption measurement. Equation (5) has then been solved numerically, thus yielding the absolute density.

A comparison of the results obtained with the two procedures outlined above gives very good agreement, as shown in figure 4 for an $\mathrm{Al}$ foil $2 \mu \mathrm{m}$ thick.

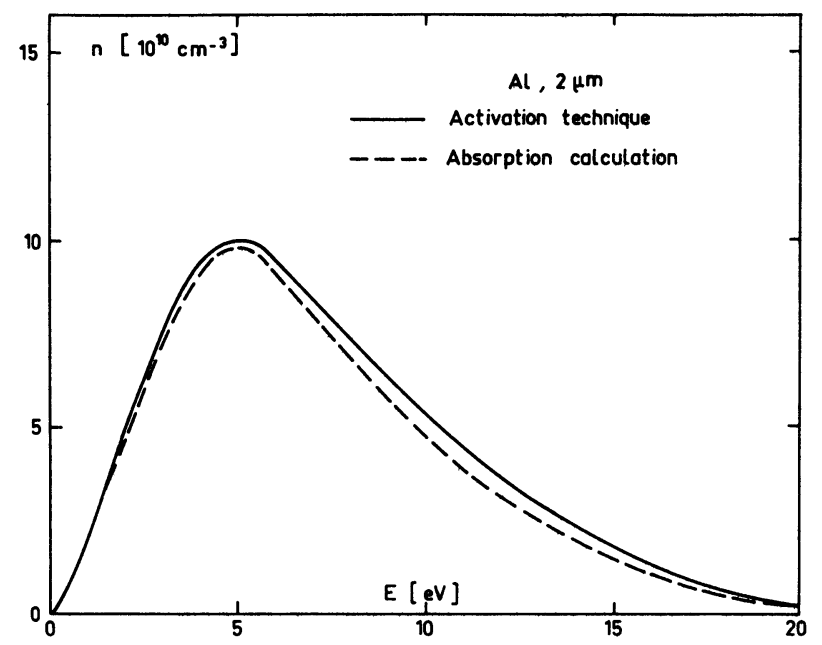

Fig. 4. - Comparison of the absolute density for a $2 \mu \mathrm{m} \mathrm{Al}$ foil obtained by neutron activation techniques (solid line) and by resonant absorption (broken line, for lamp temperature $\left.T_{\mathrm{e}}=2000 \mathrm{~K}\right)$.

In this figure, the solid line has been obtained by using the activation method in order to obtain the density scale. Note the excellent agreement (both in absolute value and in shape) between the activation curve and the absorption curve with a lamp temperature of $2000 \mathrm{~K}$ (this temperature value, resulting in a Gaussian half-width of the emitted line of $1.14 \times 10^{-2} \AA$, is given by the manufacturer. However, we have also directly measured the width of the lamp emitted line by using a vibrating Fabry-Perot interferometer, and have obtained a width of $10^{-2} \AA$ ). The agreement in shape at the highest energies is due to the fact that the Doppler width is always at least a factor of two to three less than the lamp spectral width. Finally, we have checked that the triplet structure of the Al transition used in the absorption measurements has no influence on the results.

The absorption calculation is relatively easy for $\mathrm{Al}$, but it is more difficult for $\mathrm{Ni}$ and $\mathrm{Mo}$, due to the presence of several metastable levels near the ground level. As a consequence of this problem (and of the excellent agreement obtained between the two absolute calibration methods for $\mathrm{Al}$ ), the results presented in this paper have been obtained in the following way. 
All the aluminium results have been obtained by the absorption technique, and in all cases they agree (to better than $10 \%$ ) with the activation method. On the other hand, the Ni and Mo results have been obtained by the activation method, the validity of which has been successfully shown for aluminium.

4. Experimental results. - 4.1 NeUtral BeAm OPTIMIZATION. - The first step in these experiments is to find the optimum irradiation conditions for the target under study. This is done in the following way. At a given laser energy, the focusing lens is translated along the optical axis in order to vary the energy density on target. At all laser energies, the maximum number of neutrals is obtained for the same laser density on target, with the same energy spectrum. Of course, at lower laser energies the focal surface necessary to obtain the maximum neutral density is smaller. It has therefore been decided, in order to maximize the number of neutrals, to work at the maximum laser energy $(1 \mathrm{~J})$, and vary the focal lens position. The results for a $2 \mu \mathrm{m}$ thick aluminium foil are shown in figure 5, together with the ion number measured by the charge collector. It can be seen that the number of neutrals goes through a maximum for a laser energy density of $7 \mathrm{~J} / \mathrm{cm}^{2}$; after this value, the number of neutrals decreases, while at the same time the number of ions increases. However, the number of neutrals is not the only parameter which

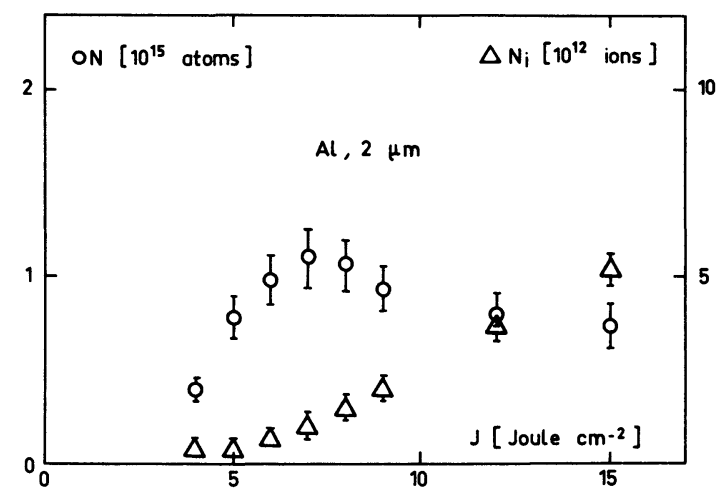

Fig. 5. - Variation of the total number of neutrals $N$ and ions $N_{\mathrm{i}}$ in $4 \times 10^{-3} \mathrm{sr}$ with laser focalization conditions.

varies when changing the energy density on target ; indeed, also their energy spectrum varies. This is illustrated in figure 6 , where the variation with energy density of the peak density energy is shown. Increasing the energy density on target increases the energy at the peak of the produced neutrals. At the same time, also the ion energy increases. Note that, for the energy density range studied here, the number of neutrals is approximately three orders of magnitude higher than that of ions, while the ion energy is one order of magnitude higher than the neutral one. Finally, although in these experiments the ions were extracted from the beam before the absorption cell,

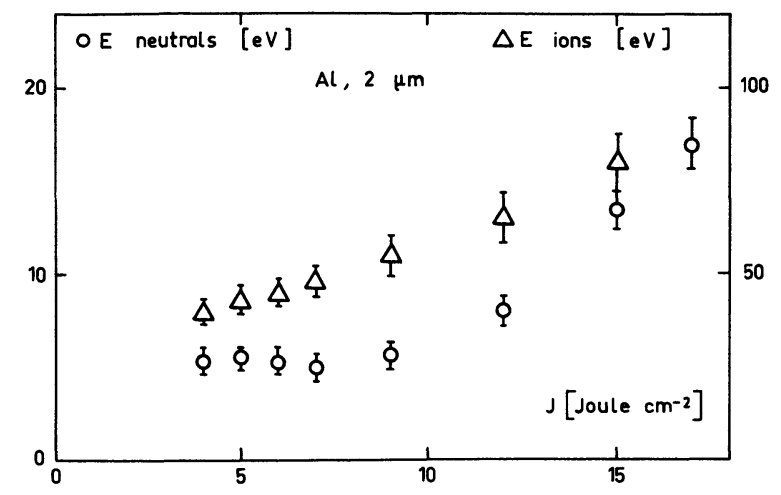

Fig. 6. - Variation of the peak energy of neutrals and ions with laser focalization conditions.

this operation is not necessary when injecting in a tokamak, since the ions are prevented from entering the plasma by the magnetic field.

4.2 VACUUM. - During the experiments described above, a variation of neutral density with vacuum condition was noticed. It was soon found out that the neutral density depends (at least for vacuum pressures higher than $10^{-6}$ torr) on the residual gas pressure. This effect was quantitatively investigated by means of a calibrated air leak, and the results are shown in figure 7. The number of atoms in the beam does not depend on the residual gas pressure for values below $10^{-6}$ torr, but it decreases with increasing pressure above this value (but without change in the energy spectrum). This effect is interpreted as due to collisions with the residual gas, scattering neutral particles out of the beam.

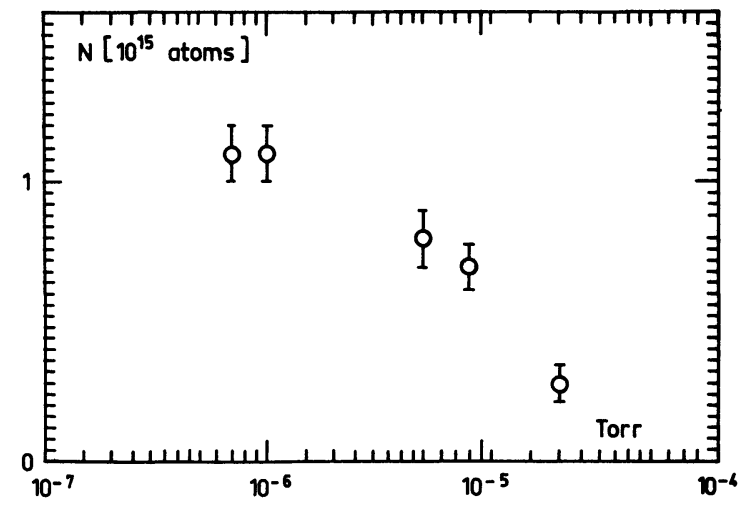

Fig. 7. - Variation of the total number of atoms in $4 \times 10^{-3} \mathrm{sr}$ as a function of background pressure in the vacuum chamber.

4. 3 TARGET THICKNESS. - It was initially thought that it would be possible to vary the number of neutral atoms by using foils of different thicknesses. This is indeed the case as shown in figure 8, for three different thickness $\mathrm{Al}$ foils. These measurements correspond in each case to the optimum laser energy density. The number of neutrals does not vary linearly with foil thickness, but this effect is mainly due to the 


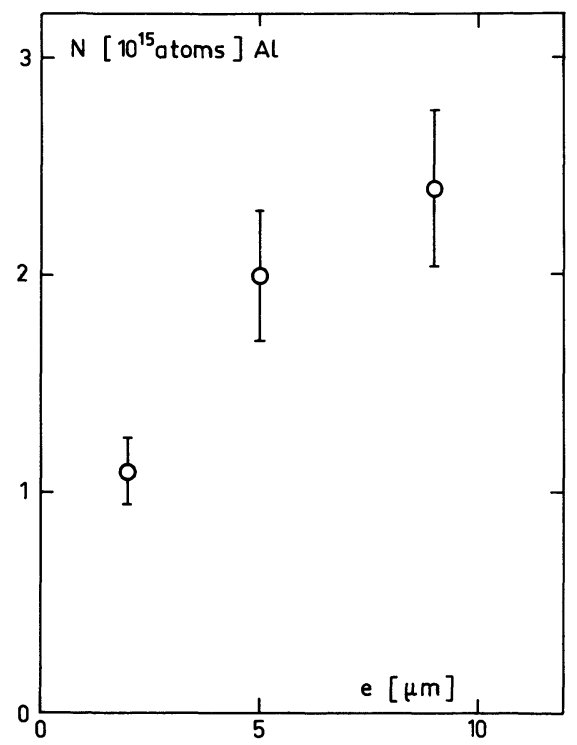

Fig. 8. - Variation of total number of neutrals in $4 \times 10^{-3} \mathrm{sr}$ with foil thickness.

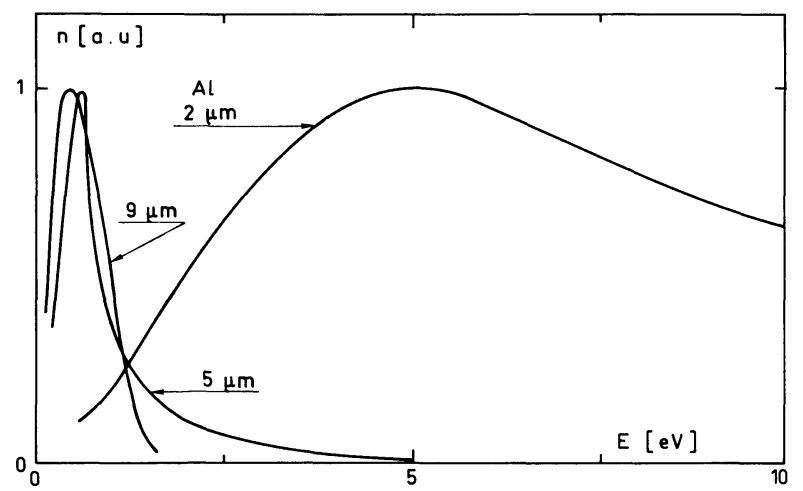

Fig. 9. - Density as function of energy for two different thickness Al foils.

focal spot variation necessary in order to work at the optimum laser energy density. Moreover, the energy spectrum is in each case very different, as shown in figure 9. Increasing the foil thickness results in a considerable decrease of the average neutral energy. The results obtained with the three different thickness Al foils are summarized in table II.

Table II.

\begin{tabular}{ccccc}
$\begin{array}{c}\text { Al thickness } \\
(\mu \mathrm{m})\end{array}$ & $\begin{array}{c}\text { J. opt. } \\
\left({\left.\mathrm{J} . \mathrm{cm}^{-2}\right)}^{-2}\right.\end{array}$ & $\begin{array}{c}\text { Neutrals in } \\
4 \times 10^{-3} \mathrm{sr} \\
\left(10^{15} \text { atoms }\right)\end{array}$ & $\begin{array}{c}\text { Peak } \\
\text { energy } \\
(\mathrm{eV})\end{array}$ & $\begin{array}{c}\text { Maximum } \\
\text { energy } \\
(\mathrm{eV})\end{array}$ \\
\hline 2 & - & - & - & - \\
5 & 7 & 1.1 & 5 & 20 \\
9 & 7.5 & 2.0 & 0.6 & 5 \\
& 8 & 2.4 & 0.4 & 1.5
\end{tabular}

Note that the variation of the number of neutrals and of their energy with laser energy density and foil thickness permits neutral beams of variable energy and density to be obtained.
4.4 Angular Distribution. - The angular distribution of the beam density, studied by translating a small $(\varnothing 1 \mathrm{~cm})$ diaphragm across the neutral beam before the absorption cell placed at the entrance of the drift tube, is shown in figure $10\left({ }^{1}\right)$. Our measure-

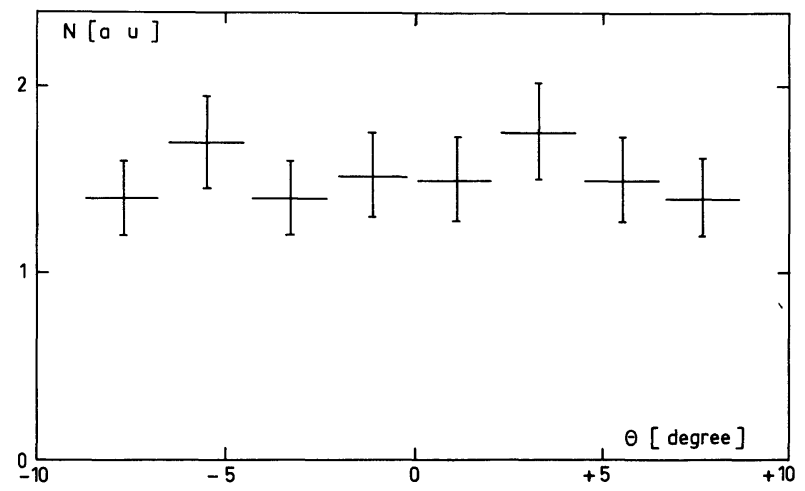

Fig. 10. - Angular distribution of aluminium neutral beam.

ments have been limited to an aperture of $\pm 8^{\circ}$, since beams of larger aperture are not normally used. The total number of neutrals $N$ (in the solid angle defined by the collimating diaphragm) is constant in the angular range studied, a result which agrees with the theory developed by Utterback et al. [12] (but which is at considerable variance with the results of Marmar et al. [6]). Of course, in order to meaningfully compare the results of figure 10 , we have checked that the energy spectrum does not change (within the experimental accuracy) over the solid angle studied here.

A consequence of this uniform distribution, is that the ratio of number of neutrals before and after the drift tube is in the exact ratio of the two solid angles (i.e., 0.08).

4. 5 Different METAL Foils. - The results obtained with the three different metals are shown in figures 11 and 12, where the density as function of energy and the energy spectrum, respectively, are shown. Note that while the $\mathrm{Al}$ and $\mathrm{Ni}$ foils were $2 \mu \mathrm{m}$ thick, the Mo foil was $4 \mu \mathrm{m}$ thick (due to the fact that we could not find thinner Mo foils, and that it is apparently not possible to obtain uniform $2 \mu \mathrm{m}$ thick Mo deposits on a glass substratum). Moreover, while the $\mathrm{Al}$ and $\mathrm{Ni}$ results shown in these figures have been obtained at the optimum laser energy density, the Mo results were obtained at a value lower than the optimum one. This is due to the fact that for $J>6 \mathrm{~J} \mathrm{~cm}^{-2}$, the molybdenum absorption measurements were severely perturbed by light emission from the neutral beam itself. This effect has already been noted by Prengel et al. [9] and

( $\left.{ }^{1}\right)$ Note that in these experiments, due to the small solid angle, the optical thin conditions is satisfied. 


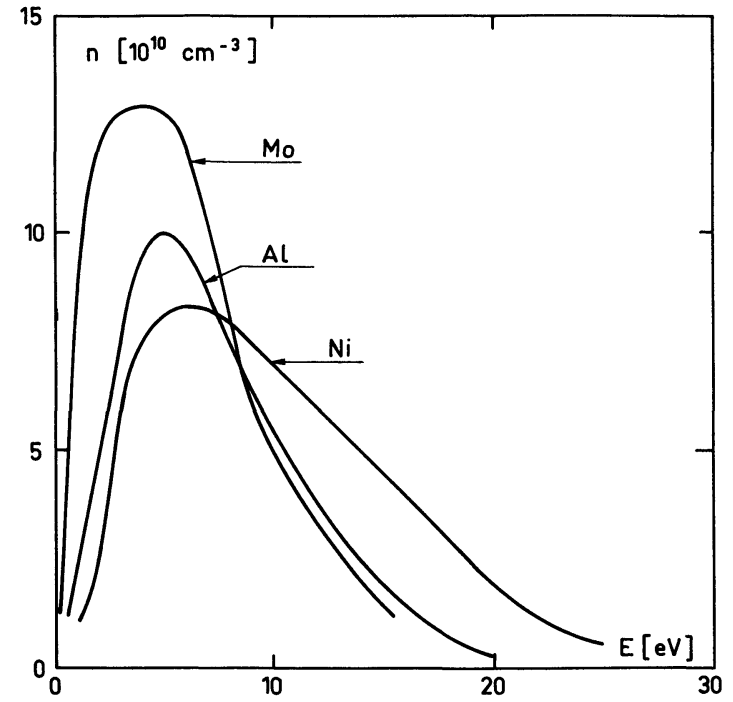

Fig. 11. - Absolute density vs. energy for three different metal beams.

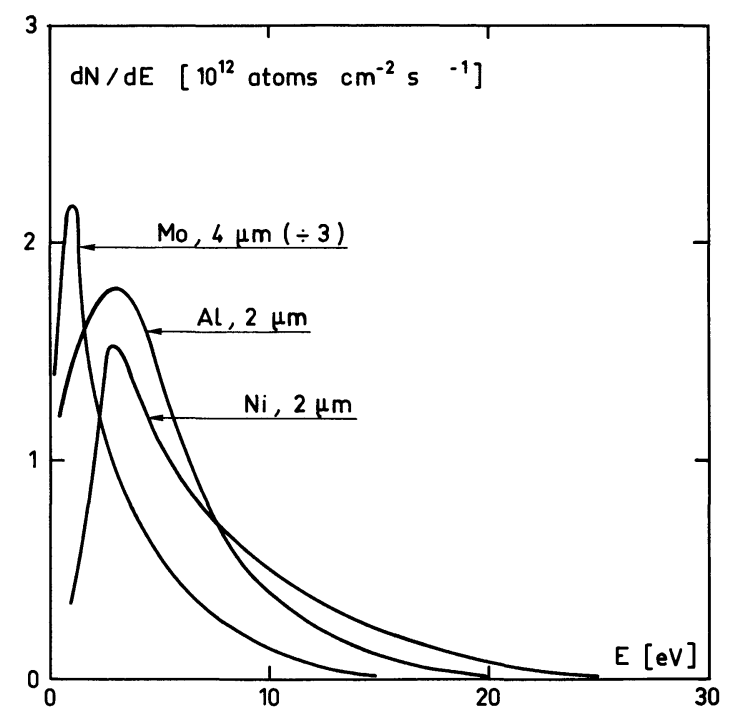

Fig. 12. - Energy spectrum of the same three beams as in figure 11 .
Marmar et al. [6] (on different metals), and it was attributed to the formation, in the target, of atoms in excited states. Of course, due to the long times of flight used in these experiments, only metastable states can be observed in the absorption region due to this mechanism. Moreover, we have measured that the beam emission signal increases with increasing pressure in the vacuum chamber, thus showing that at least a portion of the emitted light is due to collisions of the neutral atoms with the residual gas, resulting in their excitation. Light emission from the neutral beam was also observed for aluminium and nickel, but only when working with laser energy densities above $\sim 20 \mathrm{~J} \mathrm{~cm}^{-2}$.

As a consequence of the two effects mentioned above (thicker foil and laser energy density lower than the optimum value), the molybdenum beam average energy is lower than the value it would have for a $2 \mu \mathrm{m}$ thin foil (see preceeding sections), and its results cannot be directly compared with those obtained with the $\mathrm{Al}$ and $\mathrm{Ni} 2 \mu \mathrm{m}$ thin foils. A comparison of the results for these two neutral beams shows that the average beam energy is slightly higher for the $\mathrm{Ni}$ than for the $\mathrm{Al}$ beam. This effect is probably due to the higher boiling point of nickel [9].

Finally, the experimental results concerning these three targets have been summarized in table III.

5. Conclusions. - In order to prepare an impurity injection experiment on the TFR tokamak, we have studied neutral beam production by laser vaporization of thin metal foils held against a glass disc. Quantitative results have been obtained by resonant absorption experiments and confirmed by neutron activation techniques on the atoms deposited on a substratum. This technique permits to obtain short $(300 \mu \mathrm{s})$ beams of approximately $10^{15}$ useful atoms (in the $4 \times 10^{-3} \mathrm{sr}$ solid angle permitted in the injection experiment) with energies typically varying between 0.1 and $10 \mathrm{eV}$. Moreover, the energy spectrum of the injected metal beam can be varied by using different thickness foils and by varying the laser energy density on target.

Table III.

\begin{tabular}{|c|c|c|c|c|c|c|c|c|c|c|c|}
\hline \multicolumn{2}{|c|}{ Target } & \multirow{2}{*}{$\begin{array}{c}\text { Laser } \\
\text { J.opt. } \\
\left(\mathrm{J} . \mathrm{cm}^{-2}\right)\end{array}$} & \multicolumn{6}{|c|}{ Neutrals } & \multicolumn{3}{|c|}{ Ions } \\
\hline Element & $\begin{array}{c}e \\
(\mu \mathrm{m})\end{array}$ & & $\begin{array}{c}N^{\Delta} \\
\left(10^{15}\right)\end{array}$ & $\begin{array}{c}\Delta N / N \\
(\%)\end{array}$ & $\begin{array}{c}E \text { peak } \\
(\mathrm{eV})\end{array}$ & $\begin{array}{c}\Delta E / E \\
(\%)\end{array}$ & $\begin{array}{c}E \max \\
(\mathrm{eV})\end{array}$ & $\begin{array}{c}\Delta t(1 / 2)^{+} \\
(\mu \mathrm{s})\end{array}$ & $\mathrm{Ni}^{\Delta}$ & $\begin{array}{c}E \text { peak } \\
(\mathrm{eV})\end{array}$ & $\begin{array}{c}\Delta t(1 / 2)^{+} \\
(\mu \mathrm{s})\end{array}$ \\
\hline- & - & - & - & - & - & - & - & - & - & - & - \\
\hline $\mathrm{Al}$ & 2 & 7 & 1.1 & 15 & 5 & 12 & 20 & 300 & $10^{12}$ & 47 & 10 \\
\hline $\mathrm{Ni}$ & 2 & 8 & 0.9 & 20 & 6.5 & 9 & 25 & 300 & $10^{11}$ & 35 & 10 \\
\hline Mo & 4 & $6^{*}$ & 1.6 & 17 & 4 & 17 & 15 & 500 & - & - & - \\
\hline
\end{tabular}

\footnotetext{
* Not the optimum energy density (see text).

$\Delta$ In the solid angle $4 \times 10^{-3} \mathrm{sr}$ corresponding to the injection conditions in the TFR Tokamak.

+ Pulse width at half maximum at the end of the drift tube.
} 


\section{References}

[1] EQUIPE TFR, Nucl. Fusion 18 (1978) 647.

[2] Hinnov, E., Phys. Rev. A 14 (1976) 1533.

[3] Vongoeler, S., Stodiek, W., Eubank, H., Fishman, H., GrebenshChikov, S., HinNov, E., Nucl. Fusion 15 (1975) 301.

[4] TFR Group, Nucl. Fusion 17 (1977) 1297.

[5] Frilchtenicht, J. F., Rev. Sci. Instrum. 45 (1974) 51.

[6] Marmar, E. S., Cecchi, J. L., Cohen, S. A., Rev. Sci. Instrum. 46 (1975) 1149.

[7] TFR Group, Plasma Phys. 19 (1977) 587.
[8] Olstad, R. A., Olander, D. R., J. Appl. Phys. 46 (1975) 1499.

[9] Prengel, A. T., Dehaven, J., Johnson, E. H., Davidovits, P., J. Appl. Phys. 48 (1977) 3551.

[10] Anderson, J. B., Andres, R. P., FenN, J. B., in Advances in Atomic and Molecular Physics, vol. 1, edited by D. R. Bates (Academic, New York) 1965.

[11] Mitchell, A., Zemansky, M., Resonance radiation and excited atoms (Cambridge University Press, London) 1934.

[12] Utterback, N. G., Tang, S. P., Frilchtenicht, J. F., Phys. Fluids 19 (1976) 900. 